\title{
ANÁLISE DA PERCEPÇÃO DOS BOMBEIROS COMUNITÁRIOS DE SANTA CATARINA AOS RISCOS ENVOLVENDO DESASTRES
}

André Francisco Pugas ${ }^{1}$

\section{RESUMO}

O Corpo de Bombeiros Militar de Santa Catarina implementa a capacitação de agentes comunitários de proteção civil, com o objetivo de estimular as comunidades catarinenses à percepção do risco em desastres. $O$ objetivo desta pesquisa é analisar essa percepção dos riscos envolvendo desastres por meio de sua expressão gráfica. A metodologia utilizada na pesquisa é de natureza aplicada, adotando uma abordagem qualiquantitativa, de caráter exploratório, mediante pesquisa survey com questionamentos semiestruturados. A população pesquisada são os bombeiros comunitários que se encontravam na situação de ativos em 2020. Os entrevistados apresentaram resultados satisfatórios com relação a atual doutrina da Política Nacional de Proteção e Defesa Civil, como também consideraram que a capacitação os estimulou a elevar a percepção do risco de desastres. As medidas sugeridas para melhoria da percepção relacionam-se à ampliação do conteúdo dentro do programa e divulgação das informações apresentadas no contexto da comunidade em que os bombeiros comunitários convivem.

Palavras-chave: Percepção do Risco de Desastres. Agente de Proteção Civil. Bombeiro Comunitário. Defesa Civil.

\footnotetext{
${ }^{1}$ o Sargento do Corpo de Bombeiros Militar de Santa Catarina. Pós Graduado em Gestão de Riscos e Eventos Críticos - IES/CBMSC (2021). Email:pugas@cbm.sc.gov.br
} 


\title{
ANALYSIS OF THE PERCEPTION OF COMMUNITY FIREFIGHTERS OF SANTA CATARINA TO RISKS INVOLVING DISASTERS
}

\begin{abstract}
The Military Fire Brigade of Santa Catarina implements the training of community civil protection agents, with the objective of stimulating Santa Catarina's communities to perceive risk in disasters. The objective of this research is to analyze this perception of risks involving disasters through its graphic expression. The methodology used in the research is of an applied nature, adopting a qualitative and quantitative approach, of an exploratory character, through survey research with semi-structured questions. The surveyed population is the community firefighters who were in active status in 2020. The interviewees presented satisfactory results in relation to the current doctrine of the National Policy for Civil Protection and Defense, as well as they considered that the training stimulated them to raise the perception of the disaster risk. The suggested measures to improve perception are related to the expansion of the content within the program and the dissemination of information presented in the context of the community in which community firefighters live together.
\end{abstract}

Keywords: Disaster Risk Perception. Civil Protection Agent. Community Firefighter. Civil defense. 


\section{INTRODUÇÃO}

Com a evolução das técnicas e estratégias para o atendimento de ocorrências e prevenção de sinistros, juntamente com a expansão da abrangência de atendimento no território catarinense, percebeu-se a necessidade de um incremento substancial do efetivo existente no Corpo de Bombeiros Militar de Santa Catarina (CBMSC) (LAZZARIS, 1989, p.62). A alternativa encontrada foi o modelo congregador e de recrutamento de forças comunitárias, estabelecendo parcerias entre os vários níveis de poder público, com envolvimento do estado, do município e da população local, sendo denominado tal proposta como Bombeiro Comunitário (LAZZARIS, 2019).

De acordo com a Diretriz de Procedimento Administrativo Permanente (DtzPAP) Nr 2 do Comando Geral, que dispõe sobre o Programa de Expansão dos Serviços de Bombeiros do CBMSC, bombeiro comunitário, é a pessoa física que, sem remuneração e voluntariamente, atua junto às organizações do Corpo de Bombeiros Militar, sem vínculo empregatício, nos termos da Lei Federal no 9.608/98 que regula as atividades de serviço voluntário no âmbito federal e conforme o Regulamento Geral do Serviço Comunitário do CBMSC (CBMSC, 2014).

O bombeiro comunitário também pode ser definido como uma pessoa da comunidade, voluntária, capacitada pelo Corpo de Bombeiros Militar, que exerce apoio a instituição nas atividades operacionais. Eles exercem em conjunto com os bombeiros militares as funções operacionais em turnos de até 24 horas consecutivas ou em horários fracionados, sem horário fixo, dispondo seus serviços a critério de sua conveniência e a oportunidade disponibilizada pela corporação (SANTA CATARINA, 2019).

O curso de formação de bombeiro comunitário é realizado em duas etapas, Curso Básico de Atendimento a Emergências (CBAE) e Curso de Formação de Bombeiros Comunitários (CFBC). O CBMSC concede a titulação de Brigadista Voluntário e Agente Comunitário de Proteção Civil na etapa inicial 
e de Brigadista Particular na etapa final. Como agentes comunitários de proteção civil o bombeiro comunitário está apto a compreender o ciclo de gestão da defesa civil, gestão de riscos de desastres e a gestão dos desastres, dentro do contexto catarinense (CBMSC, 2018).

A Estratégia Internacional para a Redução de Desastres das Nações Unidas orienta que desastre pode ser definido como uma ruptura grave do funcionamento de uma comunidade, envolvendo perdas generalizadas de recursos humanos, materiais, econômicos e ambientais, que excede a capacidade da comunidade afetada de lidar com seus próprios recursos (ONU, 2020).

Ao mesmo tempo, em consonância com os atuais conceitos, pesquisas e considerações em relação a importância das ações de proteção e defesa civil, o dever da gestão e percepção de risco ultrapassa a competência exclusiva do Estado, estendendo o arcabouço para todos os componentes de uma sociedade organizada. A proteção civil é uma atividade desenvolvida pelo Estado e pelos cidadãos com a finalidade de prevenir riscos coletivos inerentes a situações de acidente grave, catástrofe ou calamidade, de origem natural ou tecnológica, e de atenuar seus efeitos e socorrer as pessoas em perigo, quando aquelas situações ocorram (LOURENÇO, 2009, p.192).

Nesse ínterim, o Marco de Ação de Hyogo (MAH) foi o instrumento mais importante para a implementação da redução de riscos de desastres que adotaram os Estados Membros das Nações Unidas. O MAH foi um documento assinado por 168 países, na cidade de Kobe no Japão, onde esses países firmaram o compromisso de tornar a redução dos riscos de desastres prioridade, tomar as devidas medidas cabíveis para os riscos conhecidos, estimular a conscientização e a redução dos riscos de desastres como também estar preparados para a instalação de tais eventos (POZZER; COHEN; COSTA, 2014).

Seu objetivo geral foi aumentar a resiliência das nações e das comunidades frente aos desastres ao alcançar. Ocorrida em 2005, teve como 
meta para o ano de 2015, uma redução considerável das perdas ocasionadas pelos desastres, tanto em termos de vidas humanas quanto dos bens sociais, econômicos e ambientais dos países atingidos (UNIDRS, 2012).

Para construir uma cultura de prevenção de riscos de desastres naturais em uma comunidade, é de fundamental importância conseguir diagnosticar a percepção que as pessoas possuem diante os riscos de desastres. De acordo com Oliver Smith et. al (2017) o risco de desastres e eventuais desastres podem ser considerados construções sociais externados nos eventos físicos potencialmente prejudiciais, mas que são graves e predominantemente condicionados pelas percepções de riscos de uma sociedade, das suas decisões e práticas preventivas.

Nesse contexto, essa percepção pode contribuir para obter a capacidade adequada para identificar e gerenciar riscos, ameaças e vulnerabilidades encontradas no ambiente em que vivem, de acordo com a Política Nacional de Proteção e Defesa Civil?

O objetivo desta pesquisa é analisar a percepção de risco produzida após a formação dos agentes comunitários de proteção civil para 0 gerenciamento dos riscos em desastres. Para o alcance deste objetivo foi adotado a uma metodologia survey com questionários semiestruturados, aplicados na população total de Bombeiros Comunitários que se encontravam na situação de ativos durante o período de junho a agosto de 2020 .

A escolha do tema é relevante para a organização, pois poderá auxiliar na tomada de decisões e norteará os modelos atuais de capacitação dos bombeiros comunitários.

\section{ATUAÇÃO DO CBMSC EM DESASTRES}

O Estado de Santa Catarina sofreu nos últimos anos, uma grande incidência de fenômenos adversos considerados desastres. Ávila e Mattedi (2017) descreve o fenômeno ocorrido em 2008 na região do Vale do Itajaí 
como sendo um dos maiores, resultando em uma enorme perda econômica e uma grande quantidade de vítimas, contabilizando cerca de 135 mortos e 2 desaparecidos. Devido a um período intenso de chuvas, 106 cidades que compõem 0 vale sofreram com enchentes, alagamentos, pilhagem de escombros e de movimentos de massa.

Em 2004 o Estado também sofreu com o fenômeno climático popularmente conhecido como Ciclone Catarina, que atingiu a costa sul do litoral catarinense. Fenômeno esse até então inédito na região sul do Brasil, causando a destruição de mais de 1.500 casas, além de grandes prejuízos econômicos, principalmente na agricultura regional (UFSC, 2013).

Além de outros desastres, em sua maioria relacionados ao clima, no Estado de Santa Catarina no período de 1980 até 2000, a maioria dos desastres naturais computados está associada às instabilidades atmosféricas severas, isto é, aqueles associados a decretação de situação de emergência e estado de calamidade pública (UFSC, 2013).

O órgão responsável pelo atendimento ao cidadão em caso de desastres é a Defesa Civil. Em Santa Catarina, a partir de 2019, a Defesa Civil deixou o status de secretaria e passou a estar ligada diretamente ao Gabinete do Governador do Estado.

Devido à natureza das atividades desenvolvidas pelo CBMSC, a sua atuação tem destaque logo após o evento adverso, dentro do ciclo de gestão da Defesa Civil, se restringe a atuação das guarnições na fase de resposta. Além das atribuições definidas em leis, incumbe ao CBMSC a execução de atividades de defesa civil. Nesta linha, os corpos de bombeiros tornam-se um dos principais órgãos responsáveis pela resposta neste tipo de evento (SOUZA, 2017, p.11).

Diante dos desastres onde o CBMSC foi atuante, verificou-se a necessidade de especialização da corporação nestes atendimentos. Após os 
desastres naturais ocorridos em 2008, foi criada a "Força Tarefa" para atuação em situações de desastres naturais, onde cada Batalhão do Estado possui um grupo de 12 Bombeiro Militares (SILVA, 2017, p.74).

A estrutura das Forças Tarefas (FT) teve seu fundamento no quinto eixo do Marco de Ação de Hyogo, onde trata-se de estar preparado e pronto para atuar em situações de desastres, e na Diretriz Operacional Padrão do Sistema de Comando de Operações (Dtz POP Nr-15-10-CmdoG) além de outras diretrizes internacionais vigentes como a International Search and Rescue Advisory Group (INSARAG) e Urban Search and Rescue (USAR), balizadas no modelo norte americano da Federal Emergency Management Agency (FEMA), pois sua sistemática é similar as rotinas operacionais da instituição. As forças tarefas tem por finalidade ser equipe técnica especializada, de mobilização rápida e pronta resposta no socorrimento público em casos de desastres (BABEL JUNIOR, 2016).

\subsection{Percepção do risco e desastres}

A compreensão dos diversos riscos ao qual o indivíduo está exposto no seu trabalho, no ambiente onde vive ou mesmo em uma visão macro da região onde habita depende de diversos fatores intrínsecos ao indivíduo, ao seu estilo de vida, sua bagagem cultural e aos fenômenos ao qual se vivenciou. Esse processo tanto no entendimento quanto no seu estímulo, depende de diversos aspectos devido a sua complexa e difusa materialidade (NARVÁEZ; LAVELL; ORTEGA, 2009, p.12).

Estes aprendizados envolvem um trabalho interdisciplinar de temas ligados ao cotidiano do indivíduo e à sua autopreservação. Entre outros temas estão doenças sexualmente transmissíveis, gravidez na adolescência, drogas, álcool, tabagismo e educação para o trânsito. A percepção de risco comunitária aborda o ambiente e as relações sociais que cercam a escola e a comunidade. Localizar onde estão os rios, as encostas, as histórias de fenômenos e 
desastres que aconteceram no município. Perceber as alterações do nível do rio após uma chuva intensa, ou observar as árvores após um vendaval. Tudo isso colabora para mapear os riscos da comunidade (BRÜGGEMAN, 2009, p.41).

De maneira genérica a percepção de risco a desastres está ligada ao processo de experiência e conhecimento influenciado pela historicidade de eventos adversos, o estudo geomorfológico do meio ambiente em que 0 indivíduo convive atrelado ao senso crítico e analítico, muitas vezes propiciado por instrumentos de Estado como a Defesa Civil nos seus mais diversos âmbitos como também pelas forças de segurança e projetos sociais (BRASIL, 2017).

A construção de uma cultura prevencionista deve ser difundida e estimulada em sua grande proporcionalidade por meio de aprendizado. Conceber que o ser humano, devido às diferentes realidades relacionadas a cada indivíduo, deve adotar o senso crítico para o convívio em harmonia com as vulnerabilidades e ameaças, pois, muitos deles não são passíveis de serem extintos ou mitigados (BRÜGGEMAN, 2009).

Ainda segundo BRÜGGEMAN (2009, p.85), a Organização das Nações Unidas divulga segundo suas pesquisas que para cada um dólar investido em prevenção, sete dólares são economizados durante situações de emergência. A contribuição de pequenas ações individualizadas pode influenciar positivamente na sociedade. Se todos contribuírem e adotarem ações preventivas, muitas vidas serão salvas e a qualidade de vida no planeta pode ser superior às atuais.

Compreender os riscos que nos cercam está intimamente ligado a prevenção de grandes desastres, como também os de pequena monta, pois por diversas situações o acúmulo de produtos de pequenos eventos subsequentes ou simultâneos podem aumentar o risco de uma determinada população ou diminuir a sua capacidade de superá-los (ONU, 2020). 


\subsection{Aspectos do serviço do bombeiro comunitário}

O intuito do programa bombeiro comunitário, segundo o CBMSC (2018), é proporcionar ao cidadão que de forma voluntária, seja capacitado para atuar na prevenção de sinistros de incêndios e acidentes de inúmeras naturezas, bem como auxiliar o CBMSC na coprodução do serviço público, formando na comunidade uma força organizada para reação em situações de emergência e calamidades públicas.

Uma proposta realizada em um trabalho de conclusão de curso do então Major Lazzaris na época, sugeriu uma "organização mista, cuja implantação se daria com o concurso dos poderes públicos dos diferentes níveis, em que os municípios provêm os recursos para a sua manutenção e crescimento, parece ser o desenho de uma situação futura, onde a integração [entre] Poder Público e comunidade tornaria mais ágil a resposta à demanda por segurança contra incêndios ou outros sinistros (LAZZARIS, 1989, p.62).

Lacowicz (2016) diz ainda que além de mediar o conhecimento à comunidade ampliando o acesso a conceitos e ações básicas nas áreas de prevenção de sinistros e proteção civil em casos de emergência, em sinistros de incêndios e acidentes diversos, em que existam vítimas em situação de perigo, minimizando os efeitos danosos de primeiros atendimentos realizados por pessoas leigas.

Atualmente, a formação dos bombeiros comunitários ocorre em duas etapas com finalidades diversas. Na primeira o Curso Básico de Atendimentos a Emergências (CBAE) tem como objetivo capacitar integrantes da comunidade estimulando a cultura prevencionista e reativa diante de emergências nas áreas de primeiros socorros, extinção de incêndios, sistemas preventivos em edificações e por fim noções de percepção de risco e gestão de desastres como atuação inicial e acionamento dos órgãos competentes para cada especificidade da dinâmica do desastre. Na segunda etapa, o Curso de Formação de Bombeiro Comunitário (CFBC) tem o intuito de capacitar pessoas 
da comunidade que já cursaram o CBAE para atuar em apoio a instituição nas atividades operacionais compondo as guarnições de serviço (CBMSC, 2018).

\subsection{Formação de agentes de proteção civil no CBMSC}

Considerando que as ações de proteção e defesa civil são responsabilidades fundamentais para tornar uma comunidade mais segura ou mesmo melhor preparada para realizar ações que contribuam para que eventos adversos não ocorram e minimizem seus efeitos quando já instalados naquele local. Para que essas ações estejam alinhadas com a política nacional de redução de desastres é necessário que os agentes que compõem o sistema de proteção estejam capacitados, principalmente na fase da gestão de risco, destacando-se as atividades de prevenção e preparação e mitigação dos riscos (SANTA CATARINA, 2013).

Em Portugal, por meio da Lei no 27/2006 (LEI DE BASES DA PROTEÇÃO CIVIL DE PORTUGAL, 2006) que versa sobre as bases da proteção civil surge a denominação de agentes de proteção civil. São entidades que atuam sob a direção dos comandos e chefias próprias e que exercem funções de aviso, alerta, intervenção, apoio e socorro, de acordo com as suas atribuições próprias, como Corpos de Bombeiros, Forças de Segurança, Associações Humanitárias de Bombeiros Voluntários, Serviços de Segurança, Instituições com fins de socorro e de solidariedade.

Diante das diretrizes propostas pela Estratégia Internacional das Nações Unidas para Redução de Desastres (EIRD), vários países adotaram boas práticas de países que adotaram essa proposta, objetivando incrementar 0 sistema nacional de proteção e defesa civil, inclusive o Brasil. Em análise a essa orientação internacional recai nos Corpos de Bombeiros a figura do agente de proteção civil, devido a sua participação como um dos principais atores no cenário de um desastre. 


\section{Revista FLAMMAE}

Revista Científica do Corpo de Bombeiros Militar de Pernambuco

Artigo Publicado no Vol.07 N.20 - Edição Especial 2021 - ISSN 2359-4829

Versão on-line disponível em: http://www.revistaflammae.com

No surgimento da figura do Bombeiro Comunitário no CBMSC, foi implementado na matriz curricular da formação básica conteúdos que estimulam a percepção do risco considerando o agente de proteção civil o cidadão capacitado para compor na comunidade uma força organizada de defesa civil, para atuação nas situações de emergência ou calamidades públicas durante os desastres.

\section{Figura 1 - Ciclo de Gestão da Defesa Civil}

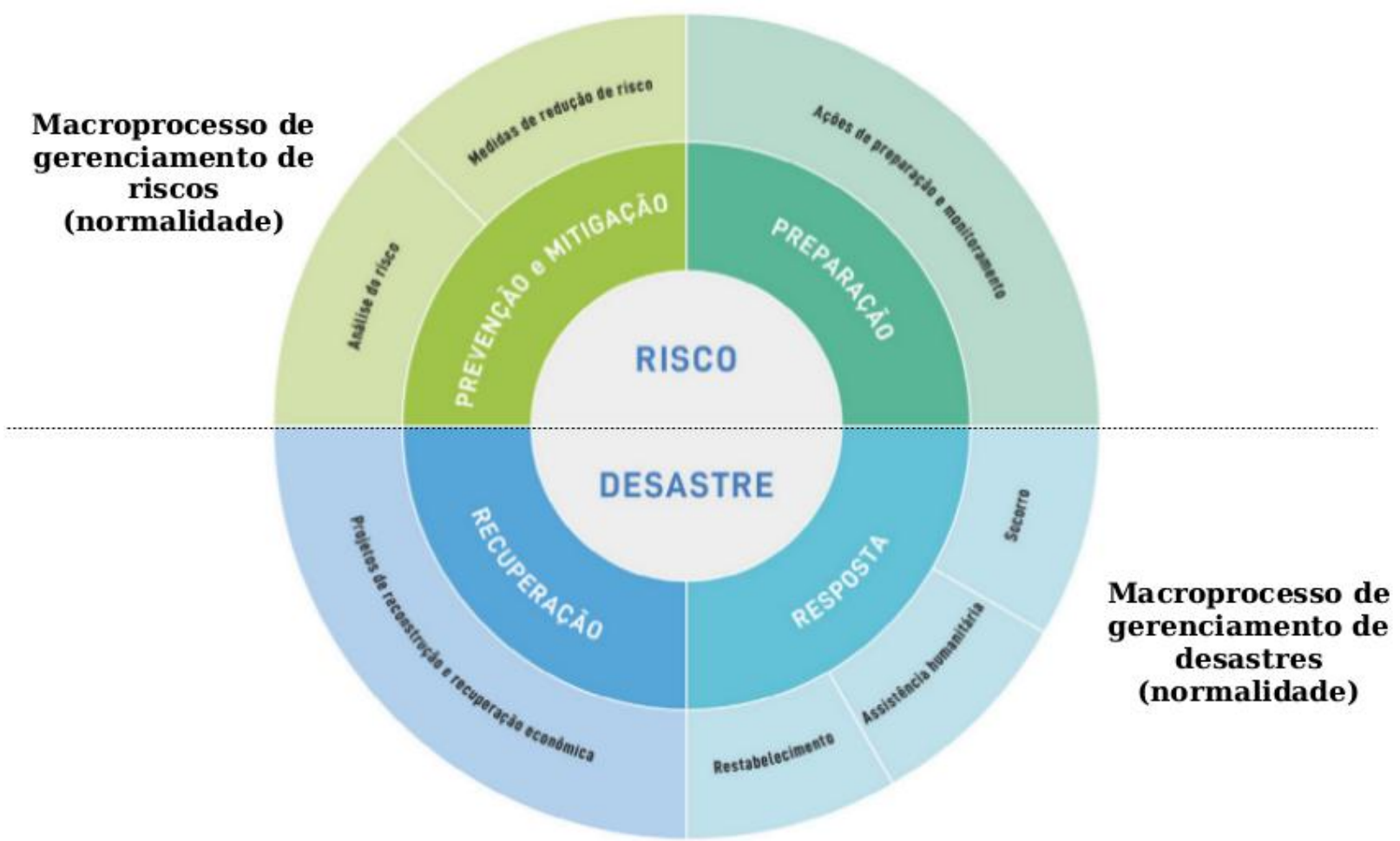

Fonte: UFSC/CEPED - 2019

O ciclo de gestão da defesa civil se divide, para fins didático-pedagógico, em gestão de risco de desastres e gestão de desastres conforme a Figura 1.

A Gestão de Riscos de Desastres requer adoção de medidas cujo objetivo é prever a redução e o controle permanente dos fatores de risco de desastre na sociedade, integrado ao desenvolvimento humano, econômico ambiental e territorial sustentável. É composta pelas etapas de prevenção e 


\section{Revista FLAMMAE}

Revista Científica do Corpo de Bombeiros Militar de Pernambuco

Artigo Publicado no Vol.07 N.20 - Edição Especial 2021 - ISSN 2359-4829

Versão on-line disponível em: http://www.revistaflammae.com

mitigação e preparação. Já a gestão de desastres consiste em planejar e realizar ações de resposta aos eventos adversos e a recuperação da infraestrutura, meio ambiente, saúde e economia da região afetada (NARVÁEZ; LAVELL; ORTEGA, 2009).

Quadro 1 - Módulo do Currículo do CBAE referente a Defesa Civil

\section{NOÇÕES DE PERCEPÇÃO E GESTÃO DE RISCOS E ATUAÇÃO INICIAL EM ACIDENTES} $8 \mathrm{~h} / \mathbf{a}$

\begin{tabular}{|c|l|c|}
\hline $\begin{array}{c}\text { Unidade } \\
\text { Didática }\end{array}$ & \multicolumn{1}{|c|}{ Assunto } & Carga horária \\
\hline 1 & Acidentes e emergências - serviços oficiais de resposta de emergência e como acionar & 1 \\
\hline 2 & Proteção civil, gestão de riscos, desastres e percepção de riscos & 1 \\
\hline 3 & Importância da prevenção na gestão de riscos e desastres, e noções de biossegurança & 1 \\
\hline 4 & Noções de como agir diante de emergências & 1 \\
\hline 5 & Exercício de percepção de risco & 1 \\
\hline 6 & \begin{tabular}{l} 
Noções de prevenção e atuação em acidentes de trânsito \\
\hline 7
\end{tabular} & $\begin{array}{l}\text { Noções de prevenção e atuação em acidentes domésticos } \\
\text { Noções de prevenção e atuação em acidentes aquáticos }\end{array}$ \\
\hline 8 & Verificação Final & 1 \\
\hline \multicolumn{1}{|c}{ Carga horária total das unidades didáticas } & $\mathbf{8}$ h/a \\
\hline
\end{tabular}

Fonte: CBMSC - 2018

Devido esses conteúdos serem apresentados em sua formação básica existe uma proporcionalidade de que a formação atinja pelo menos três vezes o número de bombeiros comunitários formados pelo CBMSC, resultado da exigência de realização de três cursos básicos para que haja um curso de formação de bombeiros comunitários (CBMSC, 2018).

É importante destacar que muitos municípios catarinenses, principalmente no interior do estado, adotam esta qualificação proporcionada pelo programa comunitário do CBMSC, para assumir funções de agentes municipais da Defesa Civil. 


\subsection{Influência da educação na redução de risco em desastres}

Segundo (SILVA, 2017. p.19) após longos anos de adaptação do ciclo de defesa civil, o grande marco na evolução do conceito de gestão de riscos de desastres teve como influência a Conferência Mundial sobre a Redução dos Desastres Naturais, que aconteceu em 2005, no Japão. Tal Marco teve como objetivo principal dotar as comunidades de capacidade para resistir aos desastres, evidenciando a importância da Redução de Riscos de Desastres, como componente essencial do desenvolvimento sustentável, diminuindo as perdas humanas, sociais, tecnológicas e ambientais.

Neste sentido a educação para a redução de risco em desastres não deve se limitar apenas aos agentes públicos ou diretamente ligado às competências constitucionais, ao contrário, deve ser amplamente difundida na sociedade e compreendida de maneira a conscientizar a população a perceber os riscos e atuar de forma proativa nas ações a reduzi-las.

Narváez, Lavell e Ortega (2009, p.43) afirmam que a gestão de risco de desastre ocorre por meio de alguns processos, como a geração do conhecimento a respeito do risco de desastre em áreas diversas áreas, evitar a instalação de riscos a desastres (prevenção), minimizar os efeitos dos fenômenos críticos (mitigação) e acesso de informações a população de como agir corretamente durante um desastre (preparação). Além também de atender a população quando deflagrado um desastre (resposta) e reconstruir áreas impactadas por estes eventos, realizando ações de recuperação social, econômica e física(recuperação). Todo esse processo de gestão de risco de desastre deve ser um processo contínuo e perene visando a compreensão intersetorial do fenômeno do desastre.

A educação comunitária é de extrema importância para que se alcance uma redução significativa dos riscos relacionados aos desastres não só no estado catarinense, mas em uma proporção mundial. As pessoas devem ser capacitadas, quando o assunto é gestão de risco de desastres em espaços 
educacionais de diversos gêneros. Essas ações podem resultar na resiliência urbana, aperfeiçoando a capacidade de uma cidade ou sistema urbano de suportar uma quantidade significativa de danos ou prejuízos decorrentes da ação dos desastres (LEICHENKO, 2011, p.53).

No CBMSC a participação neste processo de educação a redução dos riscos em desastre vem através dos programas comunitários fomentados pela instituição. Os programas comunitários visam estimular a cultura de prevenção a sinistros, além de contribuir para uma sociedade mais resiliente às adversidades decorrentes de catástrofes e emergências que impactam na segurança pública (ONU, 2020).

\section{METODOLOGIA}

\subsection{Características da população pesquisada}

Conforme a metodologia aplicada neste trabalho, utilizada para o levantamento das informações por meio de questionário do tipo survey, foi analisada a concepção que os bombeiros comunitários do CBMSC apresentam, da percepção de risco que o Curso Básico de Atendimento a Emergências (CBAE) proporcionou a essa população. Participaram da pesquisa 1446 bombeiros comunitários ativos de todo o Estado no período de junho de 2020 a agosto de 2020.

A metodologia adotada neste trabalho foi uma pesquisa de natureza aplicada com o objetivo exploratório, utilizando o método hipotético dedutivo. Para o levantamento de dados foi utilizado pesquisa survey, através de um formulário semiestruturado, com perguntas pré definidas e utilizando a escala Likert, sobre os assuntos inerentes ao conhecimento de defesa civil e percepção de risco de desastres, além da gestão dos riscos e do desastre. Para isso foi utilizada as ferramentas do Google Forms para a coleta das informações e o Infogram para produção de gráficos analíticos. 


\section{RESULTADOS E ANÁLISE DOS DADOS OBTIDOS}

Foi possível verificar que mais da metade dos bombeiros comunitários ativos neste período de estudo, em todo o Estado, são masculinos com faixa etária que varia entre 21 a 40 anos, na sua maioria. Cerca de $85 \%$ dos bombeiros comunitários apresentam um nível de escolaridade entre o ensino médio incompleto e superior incompleto. Além também de identificar que $78 \%$ dos bombeiros comunitários, apresentam um tempo de atuação nas fileiras do CBMSC entre 1 a 5 anos (Gráfico 1).

Gráfico 1 - Nível de escolaridade e faixa etária dos Bombeiros Comunitários Fonte: Dados da pesquisa
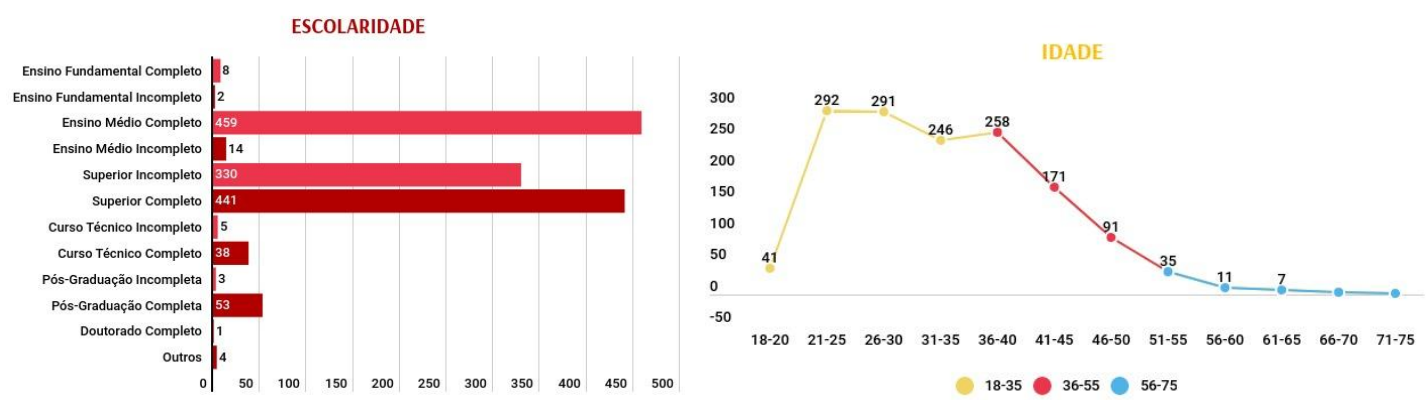

Fonte: Dados da pesquisa

Dentro dos perfis dos entrevistados foi identificado o tempo que a população pesquisada atua como bombeiro comunitário no CBMSC e como essa população está distribuída pelo Estado de acordo com os Batalhões de Bombeiro Militar aos quais cada um pertence.

Esses dados se tornam importante principalmente para poder classificar um perfil atual dos bombeiros comunitários, o que acarretará em reflexos no entendimento da percepção do risco de desastres proporcionados pelo curso, uma vez que grande parte da população pesquisada tem no máximo 5 anos de bombeiro comunitário. Ou seja, a maioria já teve sua formação com a doutrina e receberam a titulação de agentes de proteção civil, uma vez que essa grade curricular foi implementada a partir de 2015 (Gráfico 2). 
Gráfico 2 - Tempo de atuação dos Bombeiros Comunitários e qual batalhão pertencem
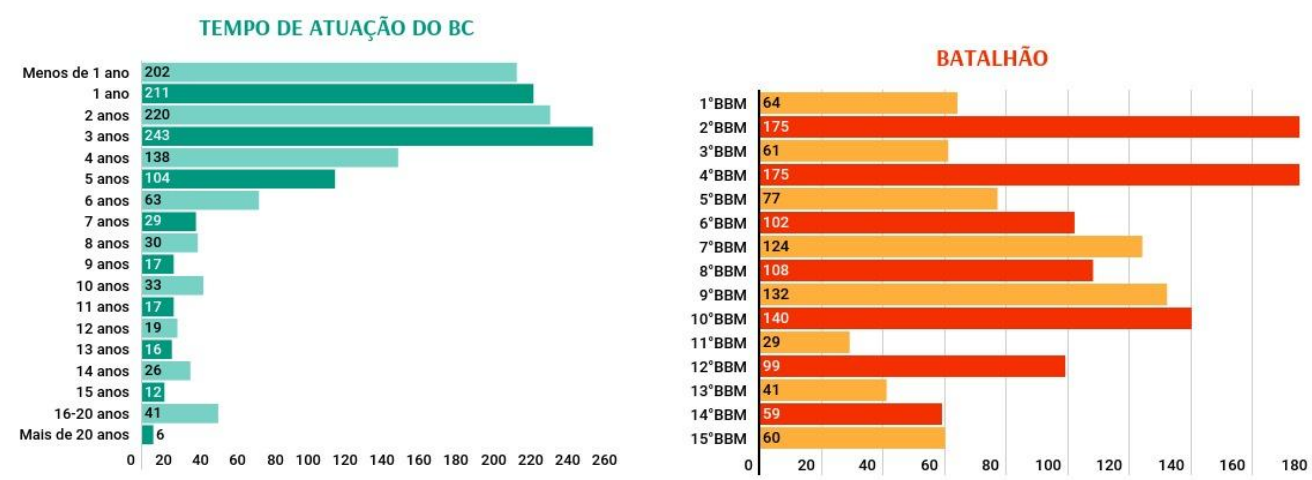

Fonte: Dados da pesquisa

\subsection{Conhecimentos sobre proteção e defesa civil}

No que concerne à análise dos conhecimentos da atual forma do ciclo de gestão da Defesa Civil, obteve-se que 56,98\% dos bombeiros comunitários estavam familiarizados com os conceitos da doutrina, enquanto $43,02 \%$ não tinham o conhecimento dessa informação (Gráfico 3).

Gráfico 3 - Percentual das respostas sobre o ciclo de gestão atual

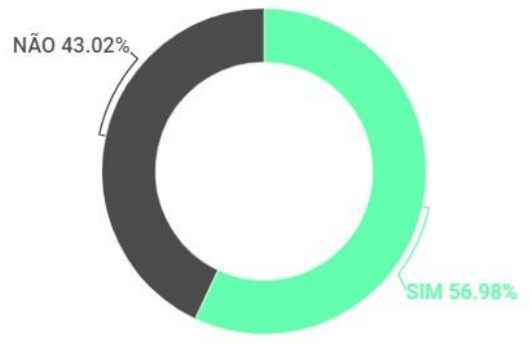

Fonte: Dados da pesquisa

Quando questionados a respeito dos conhecimentos relacionados a gestão do risco em desastres, considerando quais das fases estariam inseridas 
nesse contexto, obteve-se o resultado de que $44,26 \%$ consideram a prevenção a fase que certamente compõe a gestão do risco seguido de $19,29 \%$ que consideram que a preparação também faz parte da gestão e 16,11\% consideram que a mitigação está inserida neste processo (Gráfico 4).

Realizando o questionamento semelhante ao anterior, porém contextualizando a gestão dos desastres obtivemos o resultado de que $25,45 \%$ dos bombeiros comunitários consideram a recuperação elemento deste processo, seguido da fase de resposta com $21,65 \%$. Porém, ainda obteve o segundo maior destaque na fase de prevenção com $23,72 \%$ das respostas (Gráfico 4).

Gráfico 4 - Percentual de respostas sobre gestão de risco e gestão de desastres
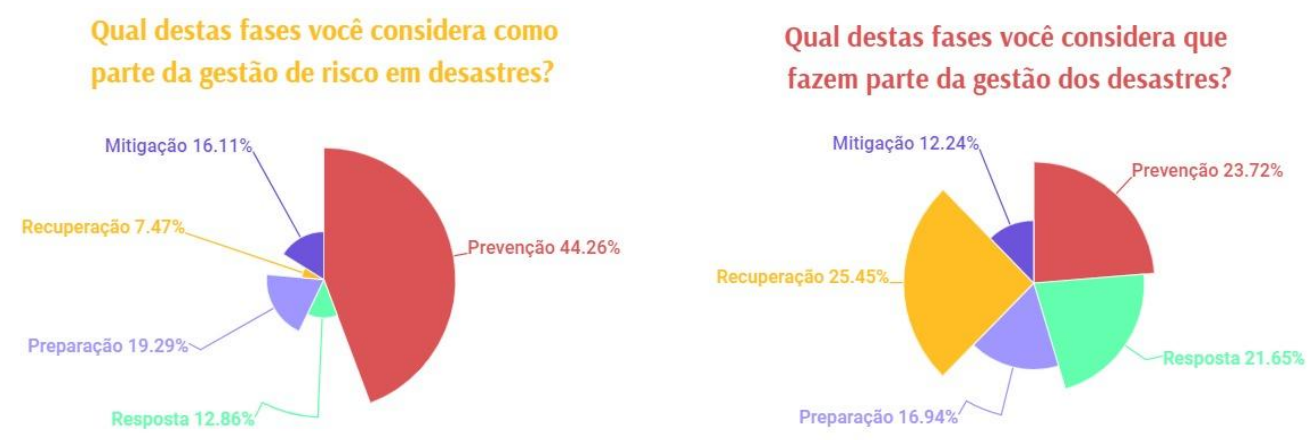

Fonte: Dados da pesquisa

Ainda realizando questionamento sobre as fases do ciclo de gestão de riscos, foi perguntado em quais fases o CBMSC estaria predominantemente inserido. Apresentando o maior destaque a fase de prevenção com 630 respostas, seguido da fase de resposta com 611 respostas (Gráfico 5).

Seguindo a análise, com o foco nos conhecimentos dos desastres, considerando quais fatores estariam relacionados com os desastres, obteve-se as respostas conforme o gráfico 5 . 
Gráfico 5 - Questionamentos sobre atuação do CBMSC e conceito de desastre
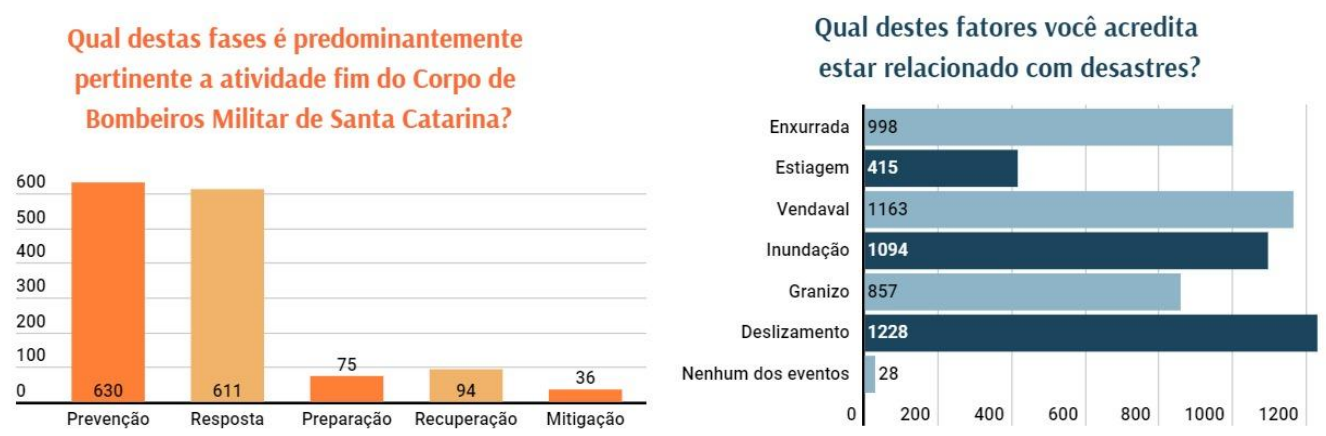

Fonte: Dados da pesquisa

O evento de deslizamentos foi considerado pela maioria como principal fator relacionado aos desastres com 1228 respostas, seguido pelas inundações e enxurradas com 1094 e 998 respostas, respectivamente. Ainda vale considerar que obteve-se 28 respostas que não consideram nenhum desses eventos relacionados com desastres.

Ao questionar os bombeiros comunitários sobre as possíveis ameaças de desastres em suas regiões, por meio da percepção de risco individual, considerando os desastres que já atingiram o nosso Estado, apresentou-se com maior destaque os vendavais com 1230 respostas, seguido por inundações com 890 respostas e granizo com 837 (Gráfico 6).

Também foi questionado aos bombeiros comunitários, agora por meio do desenvolvimento da percepção de risco individual, quais desastres já ocorreram em seu município ou região adjacente (Gráfico 6). 
Revista Científica do Corpo de Bombeiros Militar de Pernambuco

Artigo Publicado no Vol.07 N.20 - Edição Especial 2021 - ISSN 2359-4829

Versão on-line disponível em: http://www.revistaflammae.com

Gráfico 6 - Questionamentos sobre ameaças e eventos ocorridos na região dos pesquisados

Qual destes eventos você considera que podem ser

uma ameaça em seu município ou região adjacente?

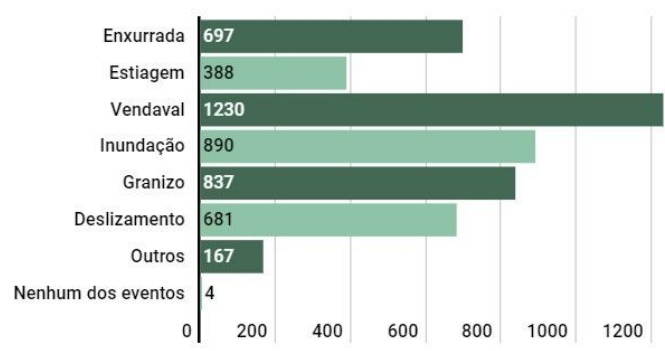

Qual destes eventos você tem conhecimento que

ocorreu em seu município ou região adjacente?

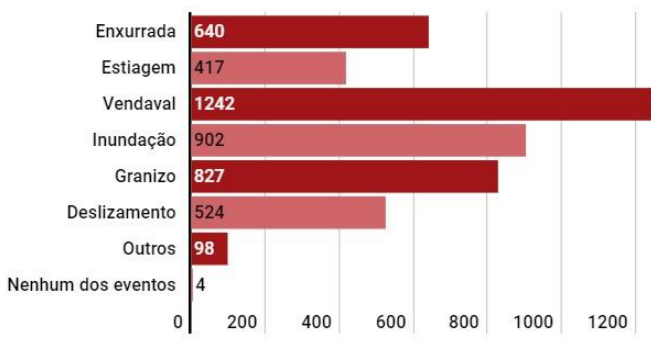

Fonte: Dados da pesquisa

Foram realizados questionamento a fim de analisar a aplicabilidade da percepção de risco dos bombeiros comunitários, se em suas regiões, os entrevistados saberiam informar quais são as vulnerabilidades ou ameaças presentes na comunidade onde vivem (Gráfico 7).

Segundo o gráfico 7, 76,97\% dos bombeiros comunitários entrevistados consideram que sabem identificar as ameaças ou vulnerabilidades, enquanto $23,03 \%$ não sabem identificar esses aspectos em suas regiões.

Gráfico 7 - Percentual sobre identificação de vulnerabilidade e definição de quais são
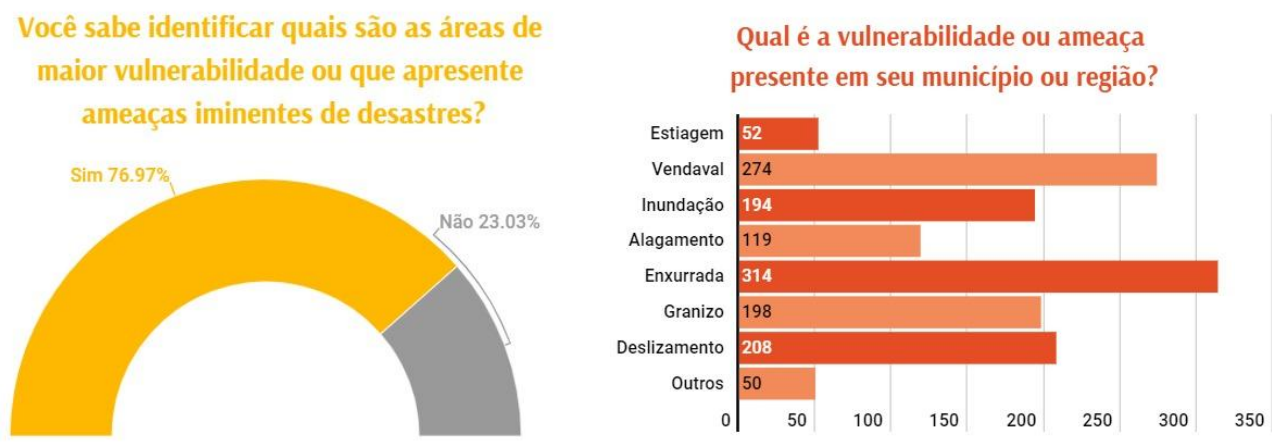

Fonte: Dados da pesquisa

Com relação ao questionamento da vulnerabilidade ou ameaça presente em sua região, as enxurradas tiveram 314 respostas, logo após os vendavais com 274 respostas e deslizamentos com 208 respostas. Granizo e inundações 
obtiveram números de resposta semelhantes, 198 e 194 respectivamente, seguido de estiagem com 52 respostas e 50 respostas considerando outras ameaças e vulnerabilidades não elencadas no questionário (Gráfico 7).

Com vista a analisar a percepção de risco em relação a disseminação das informações e o estímulo ao desenvolvimento da percepção, foi questionado aos participantes se o conhecimento adquirido no curso é disseminado dentro de suas relações sociais, segundo o gráfico $8,66,25 \%$ dos bombeiros comunitários responderam que informam aos demais membros das suas comunidades os riscos a que estão expostos, e 33,75\% afirmam que não replicam as informações.

Também foi questionado aos entrevistados se participam de Conselhos de Segurança (Conseg) em seus municípios. Somente 9,82\% participam (Gráfico 8).

Gráfico 8 - Percentual de respostas em relação informação de risco e a participação de Conseg

Você procura informar moradores dessas áreas de risco sobre os perigos que elas estão sujeitas?

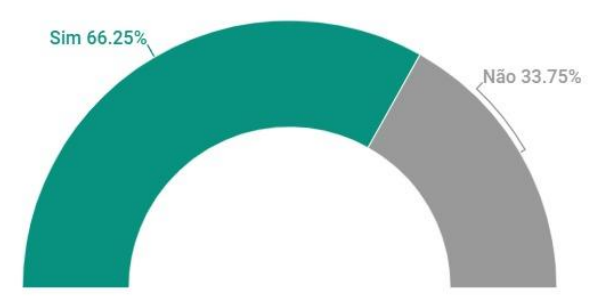

Você participa de algum Conseg (Conselhos de segurança) do seu município ou região?

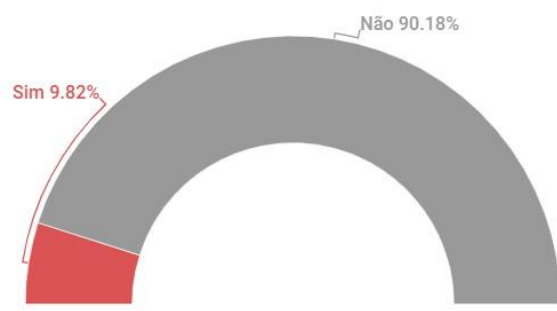

Fonte: Dados da pesquisa

Foi questionado aos bombeiros comunitários se alguma vez solicitaram ou necessitam do atendimento da Defesa Civil, sendo que 16,39\%, afirmam ter utilizado dos serviços deste órgão. Dentre os que precisaram acionar a Defesa Civil, 71,44\% ficaram satisfeitos com o atendimento (Gráfico 9). 
Revista Científica do Corpo de Bombeiros Militar de Pernambuco

Artigo Publicado no Vol.07 N.20 - Edição Especial 2021 - ISSN 2359-4829

Versão on-line disponível em: http://www.revistaflammae.com

Gráfico 9 - Percentual de respostas sobre o acionamento da Defesa Civil e nível de satisfação

Você já solicitou ou necessitou de algum tipo de atendimento diretamente da Defesa Civil?

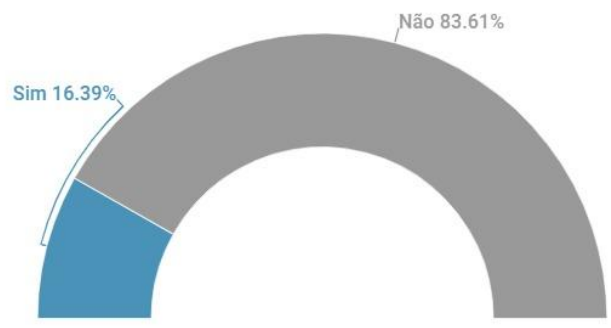

Você considera que seu atendimento prestado pela Defesa Civil foi satisfatório para a resolução do seu problema?

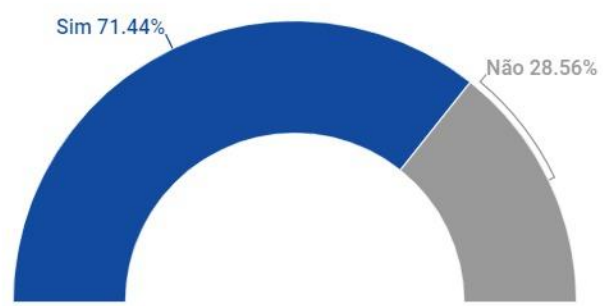

Fonte: Dados da pesquisa

Referente a questionamentos sobre a utilização da ferramenta disponibilizada pela Defesa Civil Estadual de emissão de alertas sobre eventos climáticos, Nowcasting, que é um serviço gratuito de envio de mensagens de alerta de riscos desastres e emergências por SMS onde são emitidos pela Defesa Civil de Santa Catarina, 54,56\% dos entrevistados afirmam ter seus celulares cadastrados neste serviço, bem como dentre os que têm seu telefone cadastrado, apenas $50,62 \%$ deles compartilham a existência desta ferramenta de emissão de alertas (Gráfico 10).

Gráfico 10 - Percentual de respostas sobre utilização e informação do Nowcast

Você tem seu celular cadastrado no sistema de alerta de desastres da sua região disponibilizado pela Defesa Civil Estadual?

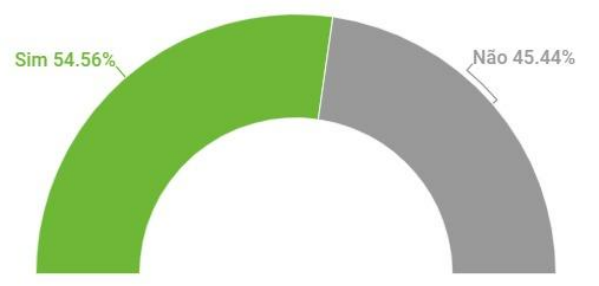

Você compartilha a informação aos amigos e familiares sobre o cadastro do celular no sistema de alerta de desastres da sua região disponibilizado pela Defesa Civil

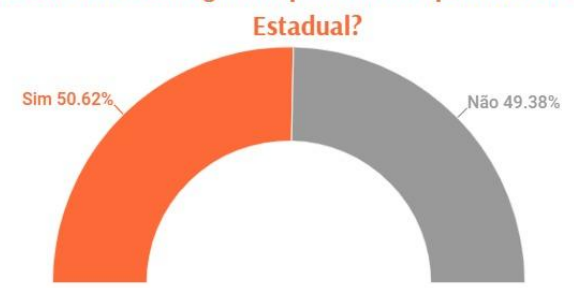

Fonte: Dados da pesquisa 
Além disso, foram realizados questionamentos aos participantes com relação a associar as informações apresentadas no curso, em relação à construção da percepção de risco e a aplicabilidade desses conhecimentos em sua região (Gráfico 11).

No aspecto de contribuição do curso para um melhor entendimento sobre a percepção de risco de desastres, cerca de $61 \%$ dos participantes consideram que a contribui plenamente (Gráfico 11).

Gráfico 11 - Número de respostas em relação a avaliação do CBAE

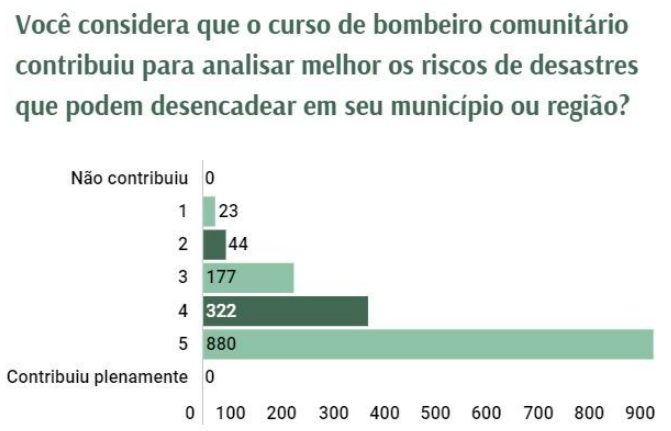

Você considera que o curso de bombeiro comunitário apresentou informações suficientes para lidar com a gestão do risco de desastres em seu município ou região?

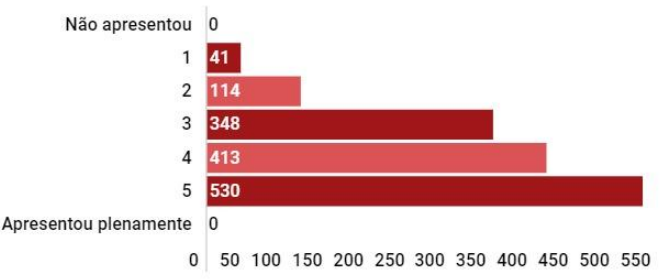

Fonte: Dados da pesquisa

Já com relação a preparação que o curso proporciona para realizar a gestão do risco de desastre, $36,65 \%$ considera plenamente apto a realizar essa etapa (Gráfico 11). Em se tratando de gestão do desastre, apenas 505 bombeiros comunitários consideram plenamente aptos a desenvolver essa etapa em um evento em sua região, caracterizando cerca de $35 \%$ da população pesquisada.(Gráfico 12)

Outro fator apurado durante essa pesquisa foi a percepção que os entrevistados têm diante da titulação de agente comunitário de proteção civil em detrimento do conteúdo abordado durante o curso de formação e sua aplicabilidade em casos concretos como apresentado no gráfico 12 . 
Revista Científica do Corpo de Bombeiros Militar de Pernambuco

Artigo Publicado no Vol.07 N.20 - Edição Especial 2021 - ISSN 2359-4829

Versão on-line disponível em: http://www.revistaflammae.com

Gráfico 12 - Número de respostas sobre as análise individual do produtos do CBAE

Você considera curso de bombeiro comunitário

apresentou informações suficientes para lidar com a

gestão de desastres em seu município ou região?

Não apresentou 0

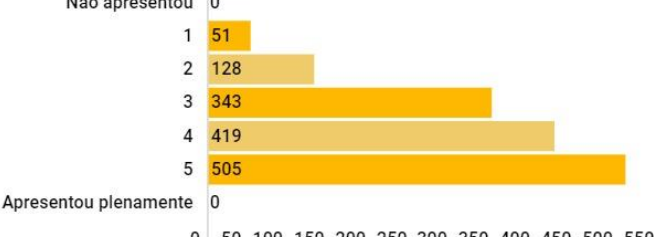

Fonte: Dados da pesquisa
Você se considera capacitado para atuar como agente comunitário de proteção civil em seu municipio ou região?

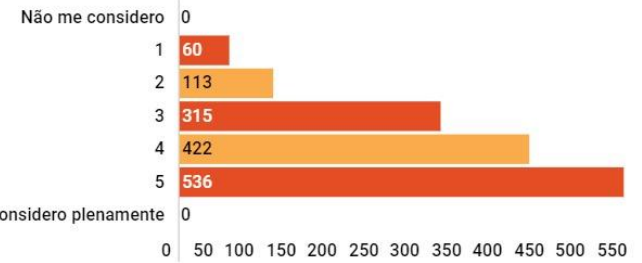

Por fim, foram os bombeiros comunitários que realizaram algumas considerações sobre a formação, em sua totalidade CBAE e CFBC, se o curso atendeu suas expectativas em relação a essas abordagens conforme o gráfico 13.

Gráfico 13 - Número de respostas sobre análise de conteúdo e expectativa do CBAE
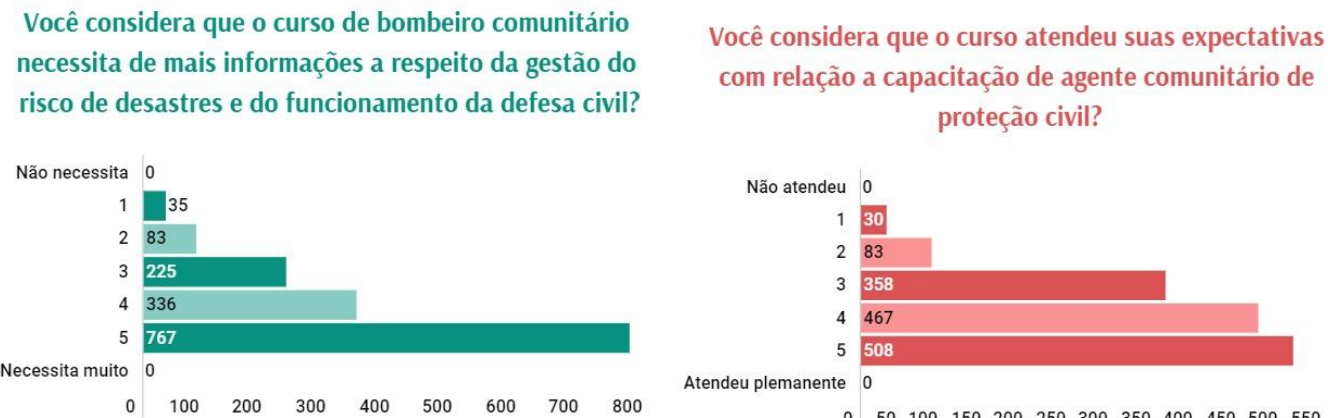

Você considera que o curso atendeu suas expectativas com relação a capacitação de agente comunitário de proteção civil?

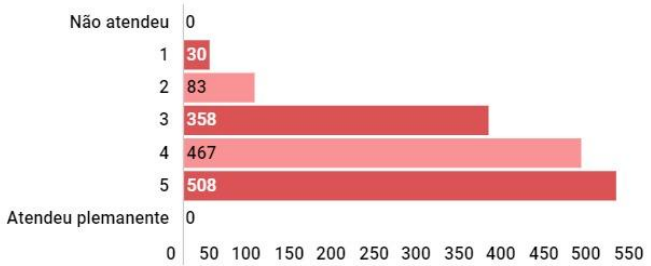

Fonte: Dados da pesquisa

\section{CONCLUSÃO}

Neste estudo foi possível identificar que em relação a doutrina atualizada empregada pela Política Nacional de Defesa Civil, e a assimilação deste 
conteúdo após a conclusão da formação do bombeiro comunitário, carece ainda de uma maior ênfase nos conceitos básicos do ciclo de gestão.

É perceptível que há o entendimento pelos participantes da pesquisa que a fase de prevenção está intimamente ligada à gestão do risco, e as fases de mitigação e preparação ainda estão um pouco aquém da sua importância.

Entretanto, considerando a análise do entendimento que a população pesquisada apresenta sobre gestão do desastre, os resultados apresentam percentuais melhores da concepção da doutrina, onde as fases de resposta e recuperação compõem a gestão do desastre. Apesar da pesquisa apontar também para que a fase de prevenção está inserida de forma equivocada no entendimento dos bombeiros comunitários pesquisados.

Outrossim, a pesquisa demonstra que apesar do CBMSC estar inserido no contexto da gestão do desastre, considerando a natureza das atividades exercidas, os bombeiros comunitários atribuem um grande valor de importância a prevenção aos desastres promovida pelo Corpo de Bombeiros.

A grande maioria dos participantes da pesquisa consideram que são capazes de identificar esses aspectos em seus municípios ou região, o que sugere que a percepção provocada durante a fase de aprendizagem da atividade de bombeiro comunitário proporciona resultados satisfatórios.

Por outro lado, a pesquisa apresenta que a adesão à difusão das informações sobre os riscos regionais identificados, que a utilização das ferramentas de alerta de desastres disponibilizados pela Defesa Civil estadual, bem como a solicitação dos serviços disponibilizados pelo próprio órgão, Defesa Civil, ainda apresentam percentuais baixos.

Vale destacar que como agentes de proteção civil além do conhecimento inerente à atividade, que tem fundamental importância na construção da percepção de risco, é necessária a difusão das informações sobre esses aspectos à população em geral. Difundir o conhecimento sobre a percepção de risco, com o objetivo de que todos, alunos do CBAE e bombeiros comunitários, sejam disseminadores dos conhecimentos adquiridos entre os membros da 
família e da comunidade, aumenta a percepção do risco de desastres, especialmente com eventos relacionados ao seu município.

Além disso, os resultados demonstram que quase $90 \%$ da população entrevistada considera ter o mínimo de condições para atuar na gestão do risco de desastres e na gestão do desastre em seus municípios, levando em consideração as peculiaridades das suas regiões. $O$ que representa uma grande confiabilidade aos cursos oferecidos pelo CBMSC, em relação aos conhecimentos inerentes à proteção e defesa civil.

Com base nos dados obtidos, o curso básico de atendimento a emergências (CBAE), que compõe a formação do bombeiro comunitário no CBMSC, apresenta um nível substancialmente relevante a produção da percepção de risco de desastres, como também a percepção de risco em outros assuntos intrinsecamente ligados à segurança.

Recomenda-se 0 incentivo a implementação de melhorias ou 0 acréscimo de conteúdos sobre os aspectos apresentados nesta pesquisa, uma vez que aproximadamente $57 \%$ dos entrevistados responderam que sabem efetivamente qual é o ciclo de gestão da defesa civil. A compreensão do funcionamento deste ciclo é fundamental para um agente de proteção civil, seja ele comunitário ou não. Pois toda a gestão do risco bem como a gestão do desastre, de maneira eficiente e protocolar, depende do domínio e implementação das fases do ciclo de gestão.

Outros fatores que corroboram com essas recomendações, fundamentase no entendimento que os entrevistados apresentaram sobre a gestão do risco. Apesar da expressividade dos $44 \%$ dos entrevistados atribuírem a prevenção como um elemento pertencente a esta fase, a preparação e mitigação que pertencem a esta fase, ambos tiveram menos da metade deste percentual. O mesmo ocorreu com relação a gestão do desastre, onde $23,72 \%$ dos entrevistados acreditam que a prevenção está inserida nesta fase. Sendo que a gestão do desastre é composta por ações de resposta e recuperação. 


\section{REFERÊNCIAS}

ÁVILA, Maria Roseli Rossi; MATTEDI, Marcos Antônio. Desastre e território: a produção da vulnerabilidade a desastres na cidade de Blumenau/SC. urbe, Rev. Bras. Gest. Urbana, Curitiba, v. 9, n. 2, p. 187-202, Aug. 2017.

BABEL JÚNIOR, Rubens José. Proposta de alteração da Lei de Taxas Estaduais para potencialização das atividades da Força Tarefa do CBMSC. 2016. 68 f. Monografia (Curso de Formação de Oficiais) - Centro de Ensino Bombeiro Militar, Corpo de Bombeiros Militar de Santa Catarina, Florianópolis, 2016.

BRÜGGEMAN, Fábio. Percepção de risco: a descoberta de um novo olhar : livro do professor. Florianópolis : Defesa civil de Santa Catarina, 2009.

CORPO DE BOMBEIROS MILITAR DE SANTA CATARINA, Instrução Geral do Serviço Comunitário IG-10-03-BM, de 27 de dezembro de 2018.

CORPO DE BOMBEIROS MILITAR DE SANTA CATARINA, Dtz PAP Nr2CmdoG, de 17 de dezembro de 2014.

UFSC. CEPED. Atlas Brasileiro de Desastres Naturais: 1991 a 2012. $2^{\mathrm{a}}$ Ed. rev. ampl. Florianópolis, 2013.

SANTA CATARINA, Defesa Civil. Gestão de Risco de Desastres. Florianópolis: Secretaria do Estado da Defesa Civil, 2013.

LACOWICZ, Altair Francisco. Programas Institucionais do Corpo de Bombeiros Militar. Florianópolis: Papa Livro, 2016.

LAZZARIS, Mílton Antônio. O Corpo de Bombeiros da Polícia Militar e a Atuação Paralela dos Bombeiros Voluntários e das Brigadas de Incêndio. 1989. Monografia (Curso Superior da Policia Militar) - Policia Militar de Santa Catarina, Florianópolis, 1989.

LAZZARIS, Milton Antônio. Emancipação: Imperativo Técnico. Edição do autor. Florianópolis, 2019.

LEICHENKO, Robin. Climate change and urban resilience. Current Opinion in Environmental Sustainability, New Jersey, v. 3, p. 164 -168, mai. 2011.

LEI DE BASES DA PROTEÇÃO CIVIL DE PORTUGAL. Lei n. 27, de 3 de julho de 2006. Lei de Bases da Protecção Civil. Lisboa. Disponível em: https://dre.pt/pesquisa/-/search/537862/details/maximized. Acesso em 29 de abril de 2021. 
Revista Científica do Corpo de Bombeiros Militar de Pernambuco

Artigo Publicado no Vol.07 N.20 - Edição Especial 2021 - ISSN 2359-4829

Versão on-line disponível em: $\underline{\text { http://www.revistaflammae.com }}$

LOURENÇO, Luciano. Os Riscos em Proteção Civil. Importância da Análise de Gestão para a Prevenção, o Socorro... e Reabilitação. Territorium. Lousã Portugal, V. 16, p. 191 - 217, Aug. 2009.

BRASIL, Ministério Da Integração Nacional. Módulo de formação: resposta, gestão de desastres, decretação e reconhecimento federal e gestão de recursos federais em proteção em defesa civil para resposta. Apostila do instrutor, Ministério da Integração Nacional, Secretaria Nacional de Proteção e Defesa Civil, Departamento de Minimização de Desastres. Brasília : Ministério da Integração Nacional, 2017.

UNIDRS, Escritório das Nações Unidas para Redução de Riscos em Desastres. Como Construir Cidades Mais Resilientes: Um guia para gestores públicos. Campanha Global 2010 - 2015. Genebra: UNIDRS, 2012.

NARVÁEZ, Lizardo; LAVELL, Allan; ORTEGA, Gustavo Pérez. La gestión del riesgo de desastres: um enfoque basado em procesos. Lima. Secretaria General de la Comunidad Andina, 2009.

OLIVER SMITH, Anthony; ALCÁNTARA-AYALA, Irasema; BURTON, lan; LAVELL, Allan. A construção social do risco de desastres: em busca das causas básicas. In: MARCHEZINI, Victor; WISNER, Ben; LONDE, Luciana R.; SAITO, Silvia M. (Org.). Reduction of vulnerability to disasters: from knowledge to action. São Carlos: RiMa Editora, 2017. pp. 97-114.

ONU, Organização das Nações Unidas. The United Nations Office for Disaster Risk Reduction.Supporting City Actions for a Resilient Future. Genebra: UNISDR, 2020.

POZZER, Camila Pinheiro; COHEN, Simone Cynamon; COSTA, Francisco da Silva. O Marco de Ação de Hyogo aplicado a gestão de risco de inundação no Brasil e em Portugal. Territorium, V. 21, p. 49 - 70, Mai. 2014.

SANTA CATARINA. Decreto no 145, de 13 de junho de 2019. Dispõe sobre a prestação de serviço voluntário nas atividades de atendimento pré-hospitalar, combate a incêndio e busca e salvamento em apoio ao Corpo de Bombeiros Militar do Estado de Santa Catarina (CBMSC) e estabelece outras providências. Florianópolis: Corpo de Bombeiros Militar de Santa Catarina, 2019.

SILVA, Alexandre da. Caracterização de movimentos de massa para gestão de risco: estudo de caso bairro Pamplona, Rio do Sul-SC. 2017. $93 \mathrm{f}$. Dissertação (Mestrado Profissional Planejamento Ambiental e Desenvolvimento Socioambiental) - UDESC, Florianópolis, 2017.

SOUZA, Davi Pereira de. O Corpo de Bombeiros Militar de Santa Catarina e a Gestão de Desastres: uma análise evolutiva da atuação da Corporação nas inundações ocorridas no município de Rio do Sul-SC nos anos de 2013 e 2015. 


\section{Revista FLAMMAE}

Revista Científica do Corpo de Bombeiros Militar de Pernambuco

Artigo Publicado no Vol.07 N.20 - Edição Especial 2021 - ISSN 2359-4829

Versão on-line disponível em: http://www.revistaflammae.com

2017. 98 f. Monografia (Curso de Comando e Estado Maior) - Centro de Ensino Bombeiro Militar / UDESC, Corpo de Bombeiros Militar de Santa Catarina, Florianópolis, 2017. 